\title{
Multicompartmental Analysis of Cholesterol Metabolism in Man
}

\author{
CHARACTERIZATION OF THE HEPATIC BILE ACID AND BILIARY \\ CHOLESTEROL PRECURSOR SITES
}

\author{
Charles C. Schwartz, Mones Berman, Z. R. Vlahcevic, L. Gregg Halloran, \\ Daniel H. Gregory, and LeON Swell, Division of Gastroenterology, \\ Departments of Medicine and Surgery, Veterans Administration Hospital, \\ and Medical College of Virginia, Richmond, Virginia 23249; and \\ Laboratory of Theoretical Biology, National Cancer Institute, \\ National Institutes of Health, Bethesda, Maryland 20014
}

A в S T RAC T The present report has presented the first clear evidence in man for the existence of specific hepatic cholesterol precursor sites associated with the formation and secretion of bile acids and biliary cholesterol. These hepatic compartments derive virtually all their cholesterol from newly synthesized and lipoprotein free cholesterol. The model which is presented was formulated on current concepts of cholesterol metabolism in man and is concerned, at this initial stage, with the elucidation of the bile acid and biliary cholesterol compartments. The complexity of cholesterol metabolism in man necessitated an initial approach that would minimize the number of inputs of cholesterol into the system, allow for the sampling of several cholesterol compartments, and permit the simultaneous labeling of newly synthesized cholesterol and preformed cholesterol. To achieve these objectives, we studied the patient with a total bile fistula. Six patients were administered simultaneously pulse injections of labeled mevalonic acid and $\left[{ }^{14} \mathrm{C}\right]$ cholesterol. The qualitative features of the specific activity time course curves after labeled mevalonic acid revealed no precursor-product relationship between bile acid, biliary cholesterol, and plasma free cholesterol. The peak specific activity of the bile acids was reached in approximately $100 \mathrm{~min}$ and was higher than the biliary cholesterol, which was higher than the plasma free cholesterol. The plasma free cholesterol specific activity became higher than the other lipids after $12 \mathrm{~h}$ and remained higher throughout the period

Received for publication 3 May 1977 and in revised form 7 October 1977. of study. Similar related observations were made with $\left[{ }^{14} \mathrm{C}\right]$ cholesterol. The data were then subjected to simulation analysis and modeling using the SAAM-27 computer program. Computer least-square fits of the data were obtained after the model was evolved. During the model development, the least number of compartments and transport pathways were introduced consistent with a good fit of the data. Of particular importance was the constraint that the model fit the data obtained from both $\left[{ }^{14} \mathrm{C}\right]$ cholesterol and labeled mevalonic acid. The same parameter values were used to fit the data from both tracers. The fluxes arrived at in the model indicate that $31 \%$ and $20 \%$, respectively, of the cholesterol input into the bile acid and biliary cholesterol precursor sites were derived directly from the newly synthesized hepatic cholesterol. The remainder had its origin predominantly from lipoprotein free cholesterol. Plasma esterified cholesterol (as free) made a small contribution $(11 \%)$ to the bile acid compartment. Similarly, $10 \%$ of the biliary cholesterol arose from an unknown hepatic site.

The present report has provided the basis for a new procedure for studying in vivo cholesterol metabolism in man. Examination of the derived cholesterol flux rates between the compartments suggests the presence of an important mechanism regulating the partitioning of lipoprotein free cholesterol between the bile acid and biliary cholesterol precursor sites. Aberrations in the proportioning of precursor cholesterol between these sites could be a causative factor precipitating the excessive secretion of biliary cholesterol and the production of lithogenic bile. 


\section{INTRODUCTION}

There is a paucity of information available on the mechanisms underlying the regulation of the anabolic and catabolic pathways of cholesterol metabolism in man. Progress in this area has been hampered by the lack of suitable procedures for studying the in vivo metabolism of cholesterol in the liver, plasma, and extrahepatic tissue compartments. Approaches to the study of cholesterol metabolism in man have generally revolved around the determination of whole body cholesterol synthesis and turnover, intestinal cholesterol absorption, and bile acid synthesis and turnover. The principal methods that have been used are the sterol balance technique, isotope dilution, and plasma cholesterol and squalene kinetics (1-12). Much of our present concept of cholesterol metabolism within the plasma-liver compartment has come from studies of plasma cholesterol kinetics (4-12). It has been customary to administer labeled cholesterol to human subjects and follow the decay of the plasma cholesterol specific activity curves over periods from 1 to 12 mo. The number of exponentials in this decay curve has been taken as the number of compartments with which plasma cholesterol interchanges. Recent studies (8-10) have defined three major body cholesterol compartments: a rapidly miscible pool (RMP), ${ }^{1}$ a slowly miscible pool, and very slowly miscible pool. It has been suggested $(9,10)$ that RMP comprises the cholesterol in the liver, plasma, RBC, and intestine. This implies that the free cholesterol of the plasma and liver are in very rapid equilibrium and may be considered as essentially one metabolic compartment from which bile acids and biliary cholesterol are derived. Estimation of whole body cholesterol turnover by the two-compartment method gave values $15 \%$ greater than the sterol balance technique (1). This discrepancy has been resolved by a longer study period and then fitting the data to three exponentials (7). Also, the major body cholesterol pool sizes have been estimated from these kinetic data $(9,10)$.

${ }^{1}$ Abbreviations used in this paper: $\mathrm{C}_{n}$, compartment number $n$ in the model; ${ }^{*} \mathrm{CHOL}$, labeled cholesterol; $\mathrm{L}_{m, n}$, fraction of material in compartment $n$ transported to compartment $m$ per minute; $\mathrm{L}_{n, n}$, fraction of material in compartment $n$ which leaves compartment $n$ per minute; $\mathrm{L}_{o, n}$, fraction of material in compartment $n$ lost irreversibly from the system per minute; $\mathbf{M}_{i}$, steady-state mass of material in compartment $i$ in micromoles; *MVA, labeled mevalonic acid $(D+L)$; NSC, newly synthesized cholesterol; $\mathrm{R}_{m, n}$, mass of material in compartment $\boldsymbol{n}$ transported to compartment $n$ per minute; $\mathrm{R}_{o, m}$, mass of material in compartment $n$ irreversibly lost from the system per minute; RMP, rapidly miscible pool (of cholesterol); $t_{n}$, duration of the delay of material in compartment $n$ in minutes; $\mathrm{U}_{i}$, rate of entry of new material into compartment $i$ from outside the system in micromoles per minute.
Recent studies in the rat (13-19) have raised questions regarding the present concept of the homogeneity of the plasma-liver cholesterol compartment. In the rat, the preferred substrate for both cholesterol $7 \alpha$ hydroxylase and the in vivo formation of $7 \alpha$-hydroxycholesterol has been shown to be newly synthesized cholesterol (NSC) (13-19). Also, bile acids appear to be derived from a precursor site which turns over much more rapidly than biliary cholesterol $(13,15)$.

An attempt was made to measure bile acid synthesis in man over a short time span $(2-6 \mathrm{~h})$, based on the premise that bile acids and biliary cholesterol arise from the RMP. However, it was noted that no consistent precursor-product relationship was present between bile acids and biliary cholesterol after the administration of labeled cholesterol, suggesting that these two sterols may not arise from a common hepatic site. In view of this observation and the recent findings $(13-19)$ in the rat that bile acids arise to a large extent from NSC, it was of interest to examine the possibility that the cholesterol precursor of the bile acids is also heterogeneous in man. Therefore, bile fistula patients without an intervening bile acid pool were administered an iv pulse of labeled mevalonic acid (20). Qualitative features of the specific activity data revealed no precursor-product relationships between bile acids, biliary cholesterol, and plasma free cholesterol. Also, the specific activities of the bile acids at their peaks were considerably higher than the specific activities of the biliary cholesterol and plasma free cholesterol. The plasma free cholesterol specific activity became higher than biliary cholesterol and bile acids after $12 \mathrm{~h}$ and remained higher throughout the duration of the study. Similar observations were made with a constant infusion of mevalonic acid. These preliminary findings (20) in man suggested that NSC may be a significant part of the substrate for bile acid synthesis and that definitive precursors may also exist within the human liver for bile acids, biliary cholesterol, and possibly lipoprotein cholesterol.

These observations provided the impetus for the present study, which has furnished evidence for the existence of definitive hepatic cholesterol compartments associated with the metabolism of bile acids and biliary cholesterol in man. A multicompartmental model was developed to describe and quantitate the metabolism of cholesterol in these hepatic compartments. Contrary to the earlier investigations of whole body cholesterol metabolism in man, which have relied on exponential curve stripping of plasma cholesterol specific activity data to derive the number of cholesterol compartments and parameters, the model developed in the present study is based on the metabolic and kinetic interrelationships of bile acids, biliary cholesterol, and plasma cholesterol. 


\section{METHODS}

Labeled compounds. The DL- $\left[5-{ }^{3} \mathrm{H}\right]$ mevalonic acid and DL- $\left[2-{ }^{14} \mathrm{C}\right]$ mevalonic acid (DBED salt) were obtained from New England Nuclear, Boston, Mass. The mevalonic acid was liberated from the DBED salt by the addition of sodium bicarbonate and the DBED was extracted with diethyl-ether. The aqueous solution of labeled sodium mevalonate was neutralized with an equimolar amount of $\mathrm{HCl}$ and diluted to a volume of $25 \mathrm{ml}$ with sterile saline. The solution was passed through a Millipore filter $(0.22$ $\mu \mathrm{m}$ ), assayed for ${ }^{3} \mathrm{H}$ or ${ }^{14} \mathrm{C}$ radioactivity and then administered to the patient within $12 \mathrm{~h}$ of preparation.

The $\left[4-{ }^{14} \mathrm{C}\right]$ cholesterol (obtained from New England $\mathrm{Nu}-$ clear) was purified by silicic acid column chromatography and stored at $-15^{\circ} \mathrm{C}$ in benzene. The radiopurity of the $\left[4-{ }^{14} \mathrm{C}\right]$ cholesterol was checked by recovery of ${ }^{14} \mathrm{C}$ activity as the digitonide and by thin-layer chromatography on silica gel $G$ using a solvent system of petroleum ether:diethyl ether:acetic acid $(89: 11: 3, \mathrm{vol} / \mathrm{vol} / \mathrm{vol})$. On the day of the experiment, the benzene was removed and the $\left[4-{ }^{14} \mathrm{C}\right] \mathrm{cho}-$ lesterol was dissolved in $0.25 \mathrm{ml}$ of absolute ethanol and slowly added to $20 \mathrm{ml}$ of human serum albumin (Cutter Laboratories, Inc., Berkeley, Calif.). This solution was assayed for radioactivity and administered to the patient within $1 \mathrm{~h}$ of preparation.

Patients. Six patients with a balloon-occludable T-tube (C. R. Bard Co., Murray Hill, N. J.) in the common bile duct were used in these studies (Table I). The patients had required cholecystectomy and choledocholithotomy for gallstones at least 11 days (range 11-34 days) before the start of the experiments. Informed consent was obtained from all patients. The patients were ambulatory and were maintained on a regular hospital diet. Liver function tests in all patients were normal except for a slight elevation of serum alkaline phosphatase. Table I shows the time period during which the T-tube was open to gravity drainage before the administration of the labeled compounds. During the period before the experiment, bile flow was continually monitored on a daily basis and generally reached a plateau between 5 and 10 days. The experiment was always started 2-4 days after each patient's bile flow reached this steady and maximal rate. At the start of the experiment, the stools were acholic as assessed by their appearance and the absence ( $<5 \mathrm{mg} /$ day) of fecal urobilinogen. The labeled compounds were administered intravenously between 10:00 a.m. and noon over a 2 -min period, except for patient I. H. who received the $\left[{ }^{14} \mathrm{C}\right]$ mevalonic acid at 4:00 p.m. Patients G. P., P. C., L. C., and T. T. were first given DL- $\left[5-{ }^{3} \mathrm{H}\right]$ mevalonic acid, and this was immediately followed by $\left[4-{ }^{14} \mathrm{C}\right]$ cholesterol in the same arm vein. Patient $I$. $H$. received DL$\left[2-{ }^{14} \mathrm{C}\right]$ mevalonic acid and then after $18 \mathrm{~h}$ was given DL- $\left[5-{ }^{3} \mathrm{H}\right]$ mevalonic acid. Patient G. A. received only DL$\left[2-{ }^{14} \mathrm{C}\right]$ mevalonic acid. The syringe was rapidly rinsed with sterile saline or albumin and then flushed into the patient. Less than $0.1 \%$ of the administered radioactivity was subsequently recovered in the syringe, needles, and i.v. tubing. Just before the administration of the labeled compounds, the balloon in the distal limb of the T-tube was inflated with a predetermined amount of saline and deflated $12 \mathrm{~h}$ later. This was done to ensure complete collection of bile, particularly during the first $12 \mathrm{~h}$ when the biliary secretion of radio-

TABLE I

Pertinent Information on Patients

\begin{tabular}{|c|c|c|c|c|c|c|c|c|}
\hline \multirow[b]{2}{*}{ Patient } & \multirow[b]{2}{*}{ Age } & \multirow[b]{2}{*}{ Weight } & \multirow{2}{*}{$\begin{array}{c}\text { Ideal } \\
\text { weight* }\end{array}$} & \multirow{2}{*}{$\begin{array}{c}\text { T-tube } \\
\text { drainage } \\
\text { before } \\
\text { label }\end{array}$} & \multirow[b]{2}{*}{ Labeled compounds administered } & \multirow{2}{*}{$\begin{array}{l}\text { Duration } \\
\text { of study }\end{array}$} & \multicolumn{2}{|c|}{ Plasma cholesterol } \\
\hline & & & & & & & Free & Ester \\
\hline & $y r$ & $k g$ & $\%$ & days & & days & \multicolumn{2}{|c|}{$\mu \mathrm{mol} / \mathrm{dl}$} \\
\hline G. P. $\S$ & 53 & 82.7 & 103 & 2 & $\begin{array}{c}105 \mu \mathrm{Ci} \mathrm{DL}\left[5-{ }^{3} \mathrm{H}\right] \text { mevalonic acid } \\
25 \mu \mathrm{Ci}\left[4-{ }^{14} \mathrm{C}\right] \text { cholesterol }\end{array}$ & 0.55 & $99 \pm 2(16)^{\prime \prime}$ & $200 \pm 12^{\prime \prime}$ \\
\hline P.C. $\S$ & 54 & 65.5 & 91 & 6 & $\begin{array}{c}137 \mu \mathrm{Ci} \mathrm{DL}\left[5^{3-} \mathrm{H}\right] \text { mevalonic acid } \\
21 \mu \mathrm{Ci}\left[4-{ }^{14} \mathrm{C}\right] \text { cholesterol }\end{array}$ & 1.06 & $63 \pm 1(10)$ & $131 \pm 7$ \\
\hline L. C. $\S$ & 64 & 72.7 & 102 & 11 & $\begin{array}{c}145 \mu \mathrm{Ci} \mathrm{DL}\left[5^{3} \mathrm{H}\right] \text { mevalonic acid } \\
30.5 \mu \mathrm{Ci}\left[4-{ }^{14} \mathrm{C}\right] \text { cholesterol }\end{array}$ & 1.31 & $69 \pm 1(14)$ & $187 \pm 2$ \\
\hline T. T. $\S$ & 82 & 89.1 & 116 & 12 & $\begin{array}{c}285 \mu \mathrm{Ci} \mathrm{DL}\left[5-{ }^{3} \mathrm{H}\right] \text { mevalonic acid } \\
49.8 \mu \mathrm{Ci}\left[4-{ }^{14} \mathrm{C}\right] \text { cholesterol }\end{array}$ & 6.02 & $59 \pm 1(28)$ & $178 \pm 5$ \\
\hline I. H.ף & 49 & 65.9 & 100 & 13 & $105 \mu \mathrm{Ci} \mathrm{DL}\left[5-^{3} \mathrm{H}\right]$ mevalonic acid & 4.03 & $90 \pm 1(19)$ & $194 \pm 3$ \\
\hline I. H.ף & 49 & 65.9 & 100 & 12 & $70 \mu \mathrm{Ci} \mathrm{DL}\left[2-{ }^{14} \mathrm{C}\right] \mathrm{mevalonic}$ acid & 4.83 & $90 \pm 1(19)$ & $194 \pm 3$ \\
\hline G. A. & 83 & 56.4 & 90 & 25 & $112 \mu \mathrm{Ci} \mathrm{DL}\left[2-{ }^{14} \mathrm{C}\right]$ mevalonic acid & 5.25 & $68 \pm 1(46)$ & $157 \pm 3$ \\
\hline
\end{tabular}

* Metropolitan Life Insurance Company Statistical Bulletin 40, 1959.

$\$$ Time period the T-tube was open to gravity drainage before administration of the labeled compounds. In patient G. P., the T-tube was open to gravity drainage for 9 consecutive days postoperatively, clamped for $36 \mathrm{~h}$, and opened again to gravity drainage for 2 days before the study.

$\S$ These patients received $\left[5-{ }^{3} \mathrm{H}\right]$ mevalonic acid and $\left[4-{ }^{14} \mathrm{C}\right]$ cholesterol simultaneously.

"Mean \pm SE during the period of study after administration of labeled compounds. Number of determinations indicated in parentheses.

I This patient received $\left[2-{ }^{14} \mathrm{C}\right]$ mevalonic acid initially and then after $18 \mathrm{~h}$ was administered $\left[5-{ }^{3} \mathrm{H}\right] \mathrm{mevalonic}$ acid. 
activity was changing rapidly. Thus, the balloon eliminated the possibility of any recirculating radioactive bile acids during the critical period. It was noted that the rate of bile flow with the balloon inflated was constant and was similar to that which was obtained during gravity drainage alone. Bile was collected for short intervals $(5,15$, or $30 \mathrm{~min})$ during the first $4 \mathrm{~h}$ after the administration of the labeled compounds, and for longer intervals until the conclusion of the experiment as indicated in the legends to Figs. 2-7. Approximately $5 \mathrm{ml}$ of venous blood was collected in a heparinized syringe at frequent intervals as shown on the figures. Each blood sample was immediately centrifuged for $5 \mathrm{~min}$ at 3,000 rpm to separate the plasma.

Methods. Aliquots of bile and plasma were immediately extracted with $20 \mathrm{vol}$ of $2: 1$ chloroform-methanol and washed with $1 / 5 \mathrm{vol}$ of water, according to Folch et al. (21). The chloroform phase of the bile was analyzed for phospholipid phosphorous by the method of Bartlett (22). Biliary free cholesterol was precipitated as the digitonide and dissolved in methanol. Cholesterol mass was determined on an aliquot by the method of Sperry and Webb (23), and another aliquot was assayed for ${ }^{3} \mathrm{H}$ and ${ }^{14} \mathrm{C}$ radioactivity by liquid scintillation counting. Bile acids (mass and radioactivity) were determined by a combination of thin-layer chromatography and gas-liquid chromatography, as described earlier $(3,24)$. Aliquots of the methanol-water phase were autoclaved with $\mathrm{KOH}$ and neutralized with $\mathrm{HCl}$. The bile acids were then extracted with diethyl ether and the methyl esters prepared with diazomethane. An aliquot of the methyl esters was subjected to gas-liquid chromatography to quantitate the individual bile acids; $5 \alpha$-cholestane was used as an internal standard. The stationary phase was $3 \%$ HI EFF 8BP (Applied Science Labs, Inc., State College, Pa.). Another aliquot of the bile acid methyl esters was subjected to thin-layer chromatography on silica gel $G$ using the solvent system of ethyl acetate:isooctane:acetic acid (5:5:1, vol/vol/ vol). The methyl cholate and methyl chenodeoxycholate zones were isolated and eluted from the silica gel. The bile acid mass in each zone was determined by gasliquid chromatography; radioactivity $\left({ }^{3} \mathrm{H}\right.$ and $\left.{ }^{14} \mathrm{C}\right)$ was determined by liquid scintillation counting. Bile acid specific activities (in disintegrations per minute per micromole) were corrected for the loss of ${ }^{3} \mathrm{H}$ and ${ }^{14} \mathrm{C}$ activity during the conversion of cholesterol to bile acids (25) and for procedural loss (15). Specifically, after DL- $\left[5-{ }^{3} \mathrm{H}\right]$ mevalonic acid administration, cholic acid $(3 \alpha, 7 \alpha, 12 \alpha$-trihydroxy-5 $\beta$ cholestan-24-oic acid) ${ }^{3} \mathrm{H}$ activity was increased by $1 / 12$ to account for ${ }^{3} \mathrm{H}$ loss when the $12 \alpha$-hydroxyl group was inserted on the ring during its biosynthesis. When DL-[2${ }^{14} \mathrm{C}$ ]mevalonic acid was given, there was loss of $1 / 6$ of ${ }^{14} \mathrm{C}$ carbons during the conversion of squalene to cholesterol. No correction was made in the specific activities for the loss of ${ }^{14} \mathrm{C}$ activity, because cholic and chenodeoxycholic acids $(3 \alpha, 7 \alpha$-dihydroxy- $5 \beta$-cholestan- 24 -oic acid) and cholesterol were equally affected. However, this ${ }^{14} \mathrm{C}$ activity loss was taken into account when estimates of mevalonate conversion to cholesterol were calculated. Also, after the administration of DL- $\left[2-{ }^{14} \mathrm{C}\right]$ mevalonic acid, a $1 / 5$ correction in the specific activities of cholic and chenodeoxycholic acids was necessitated by the loss of ${ }^{14} \mathrm{C}$ activity at $\mathrm{C}-26$ during the biosynthesis of the bile acids from the biosynthetically labeled cholesterol. A 1/6 correction was applied to the bile acid ${ }^{3} \mathrm{H}$ specific activities for procedural loss of ${ }^{3} \mathrm{H}$ activity during the hydrolysis of the bile acid conjugates (15).

The homogeneity of the mass and radioactivity in the cholic and chenodeoxycholic acid thin-layer chromatography zones was verified by recrystallization to constant specific activity and by silicic acid column chromatography (26).
There was no change in the specific activity of the cholic acid and chenodeoxycholic acid fractions on repeated recrystallization (four times) from methanol-water, acetone-water, or acetone-hexane. Both bile acid mass and radioactivity paralleled one another when eluted from silicic acid with acetonebenzene; only one peak of either cholic or chenodeoxycholic acids was noted.

Plasma free and esterified cholesterol were separated by silicic acid column (Bio-Sil HA, minus 325 mesh, Bio-Rad Laboratories, Richmond, Calif.) chromatography (27). The esterified cholesterol fraction was hydrolyzed and precipitated with digitonin (23). The digitonide precipitate was dissolved in methanol and aliquots taken for mass determination (23) and liquid scintillation counting. Plasma free cholesterol mass was determined by GLC using $5 \alpha$ cholestane as an internal standard. The stationary phase was 3\% SP-2401 (Supelco, Inc., Bellefonte, Pa.). Carrier free cholesterol was added to another aliquot of the plasma free cholesterol fraction before digitonin precipitation; the digitonide was dissolved in methanol, and radioactivity was determined by liquid scintillation counting.

Radioactivity $\left({ }^{3} \mathrm{H}\right.$ and[or] $\left.{ }^{14} \mathrm{C}\right)$ was determined by liquid scintillation counting (Mark III, Searle Analytic Inc., Des Plaines, Ill.); quench correction was applied using the external standard method.

Experimental design. The complexity of cholesterol metabolism in man necessitated an initial experimental approach that would minimize the number of inputs of cholesterol into the system, allow for the sampling of several cholesterol compartments, and permit the labeling of both newly synthesized and preformed cholesterol simultaneously. To achieve these objectives, we selected the bile fistula patient over the patient with an intact enterohepatic circulation particularly during this stage of the development of the cholesterol compartmental model. The following points are pertinent with regard to the selection of the bile fistula patient model: $(a)$ the bile acids secreted are newly synthesized and as such are derived from the hepatic cholesterol precursor site; there is no recirculating bile acid pool; $(b)$ biliary cholesterol is also derived directly from its site of origin in the liver; $(c)$ since there is no cholesterol absorption in this patient, it is not necessary to account for exogenous sources of cholesterol for biliary cholesterol or bile acid synthesis; $(d)$ the total net input of cholesterol into the plasma-liver system is equal to the sum of the secretion rates of bile acids and biliary cholesterol, since there is no other significant loss of cholesterol via other routes; $(e)$ when all the bile is allowed to drain externally via the T-tube for several days, maximal bile acid synthesis is reached; thereafter, bile acid synthesis, biliary cholesterol secretion, and plasma cholesterol concentration tend to remain constant (see Tables I and II and Fig. 1). This approach has afforded an opportunity to construct a model based on the exchange of tracers between compartments, rather than on the number of exponentials in the specific activity decay curves. The specific activity data obtained for the bile acids, biliary cholesterol, and plasma free and esterified cholesterol were subjected to simulation and modeling analysis using the SAAM-27 computer program (28).

\section{RESULTS}

Biliary lipid secretion. The biliary lipid secretion data for each of the patients are shown in Table II. In each patient, the secretion of biliary cholesterol, 
TABLE II

Biliary Lipid Secretion

\begin{tabular}{lrrrrrr}
\hline Patient & Phospholipid & Cholesterol & Cholic acid & $\begin{array}{c}\text { Chenodeoxycholic } \\
\text { acid }\end{array}$ & TBA* $^{*}$ & Cholesterol \\
\hline & & & $\mu$ mollmin & & & $\begin{array}{c}\text { percent total } \\
\text { lipid }\end{array}$ \\
G. P. (22) & & & & & \\
& & & & & & \\
& \pm 0.16 & \pm 0.11 & \pm 0.22 & \pm 0.12 & \pm 0.35 & \pm 0.9 \\
P. C. (62) & 2.30 & 1.05 & 2.80 & 3.47 & 6.28 & 11.0 \\
& \pm 0.05 & \pm 0.02 & \pm 0.04 & \pm 0.05 & \pm 0.09 & \pm 0.2 \\
L. C. (60) & 2.54 & 0.88 & 4.37 & 2.16 & 6.54 & 9.1 \\
& \pm 0.07 & \pm 0.02 & \pm 0.12 & \pm 0.07 & \pm 0.19 & \pm 0.2 \\
T. T. (77) & 2.09 & 1.24 & 1.96 & 1.60 & 3.56 & 18.0 \\
& \pm 0.05 & \pm 0.03 & \pm 0.05 & \pm 0.05 & \pm 0.08 & \pm 0.3 \\
I. H. (29) & 2.34 & 0.99 & 2.73 & 1.81 & 4.54 & 12.6 \\
& \pm 0.05 & \pm 0.03 & \pm 0.07 & \pm 0.04 & \pm 0.11 & \pm 0.4 \\
G. A. (97) & 1.82 & 0.91 & 2.57 & 1.70 & 4.27 & 13.4 \\
& \pm 0.07 & \pm 0.03 & \pm 0.11 & \pm 0.07 & \pm 0.17 & \pm 0.4 \\
\hline
\end{tabular}

* Total bile acids.

$\$$ Number of determinations for each biliary lipid is indicated in parentheses.

$\S$ Mean \pm SE of all bile samples collected after administration of labeled compounds.

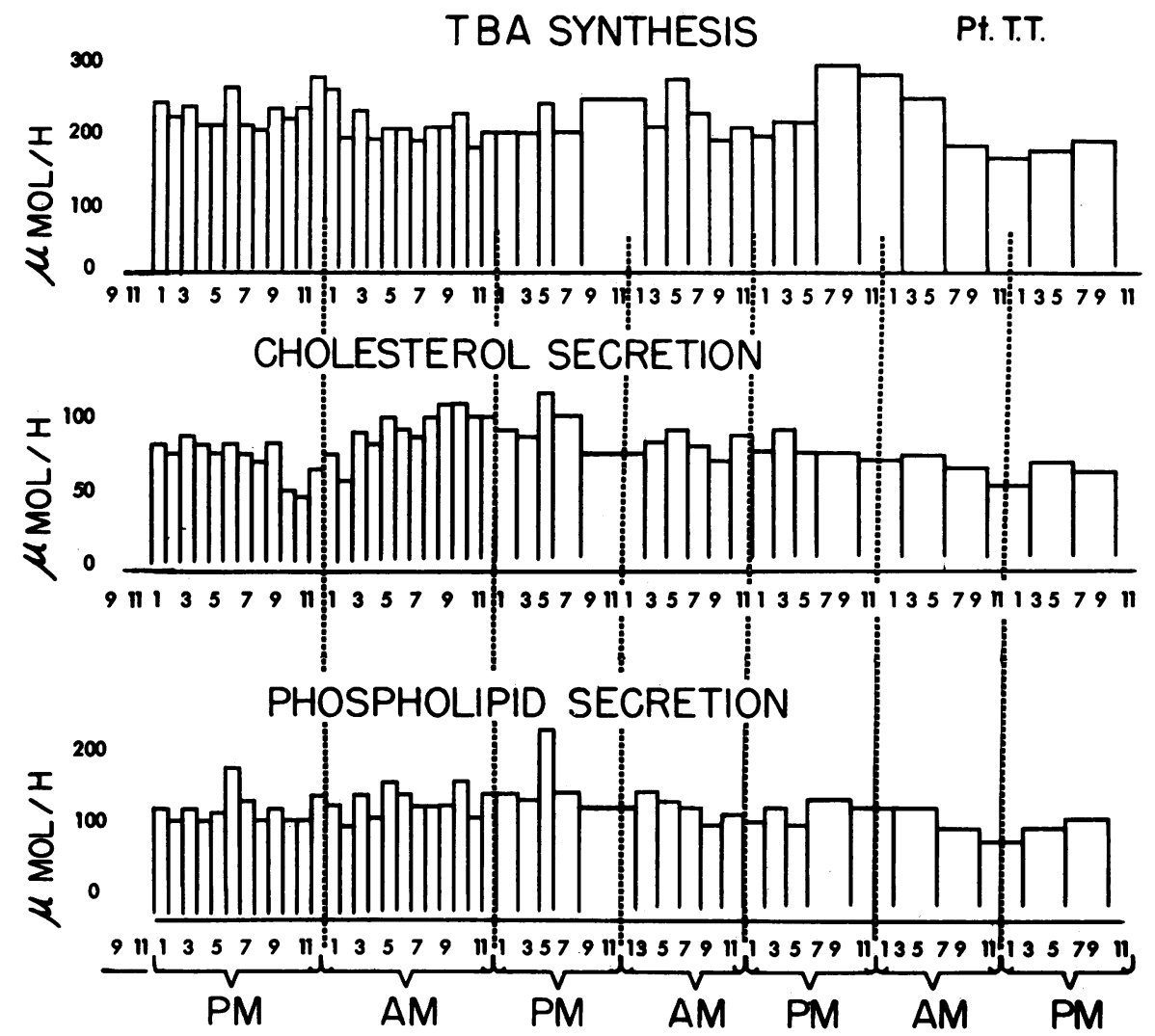

Figure 1 Total bile acid secretion (synthesis), biliary cholesterol, and phospholipid secretion rates in a bile fistula patient (Pt. T. T.) during the period of study. 
cholic acid, and chenodeoxycholic acid during the period of study was relatively constant, as evidenced by the small degree of variability. This is illustrated graphically in Fig. 1, which shows the biliary lipid secretion rates for a typical patient over a 4-day study period. There was no trend in the pattern of bile acid secretion either upward or downward during the day or from day to day throughout the period of study. The synthesis of cholic acid, chenodeoxycholic acid, and total bile acids were increased approximately sixfold over normal subjects (3). The ratio of cholic to chenodeoxycholic acid synthesis was 1.4 as compared with 1.8 in the normal. No secondary bile acids (deoxycholic acid [ $3 \alpha, 12 \alpha$-dihydroxy-5 $\beta$-cholestan-24oic acid] and lithocholic acids [ $3 \alpha$-monohydroxy- $5 \beta$ cholestan-24-oic acid]) were detected in the bile of these patients throughout the study, suggesting total interruption of the enterohepatic circuit and quantitative collection of hepatic bile. The biliary cholesterol secretion rates in these patients did not reveal an upward or downward trend during the period of study and ranged between 0.88 and $2.58 \mu \mathrm{mol} / \mathrm{min}$. As indicated in Table II, all patients secreted bile which had a relatively high percentage of cholesterol, as would be expected in the absence of a recirculating bile acid pool.

Specific activity data. The specific activities of cholic acid, biliary cholesterol, and plasma free and esterified cholesterol after the administration of labeled mevalonic acid or cholesterol are shown in Fig. 2-7. The chenodeoxycholic and cholic acid specific activity time course curves were essentially the same in each patient after the administration of either labeled mevalonic acid or $\left[{ }^{14} \mathrm{C}\right]$ cholesterol. Therefore, for purposes of clarity, only the cholic acid specific activities are shown. This virtual identity of the bile acid specific activities can be taken as evidence that cholic and chenodeoxycholic acids are derived from a common hepatic cholesterol precursor site in man. Several qualitative features are evident from the specific activity curves after the administration of isotopic mevalonic acid. In all of the patients studied, there were no classic precursor-product relationships noted between the plasma free cholesterol, bile acids, and biliary cholesterol. The rate of buildup of radioactivity was most rapid in the bile acid fraction, followed by biliary cholesterol, plasma free cholesterol, and then plasma esterified cholesterol. At their respective peak specific activities, the bile acids exceeded the biliary cholesterol, which in turn exceeded the plasma free fraction. The plasma esterified cholesterol specific activity built up very slowly and did not equilibrate with the plasma free fraction until about 1-2 days. From approximately $720 \mathrm{~min}$ until the conclusion of the study, the specific activity of the bile acids and biliary choles-

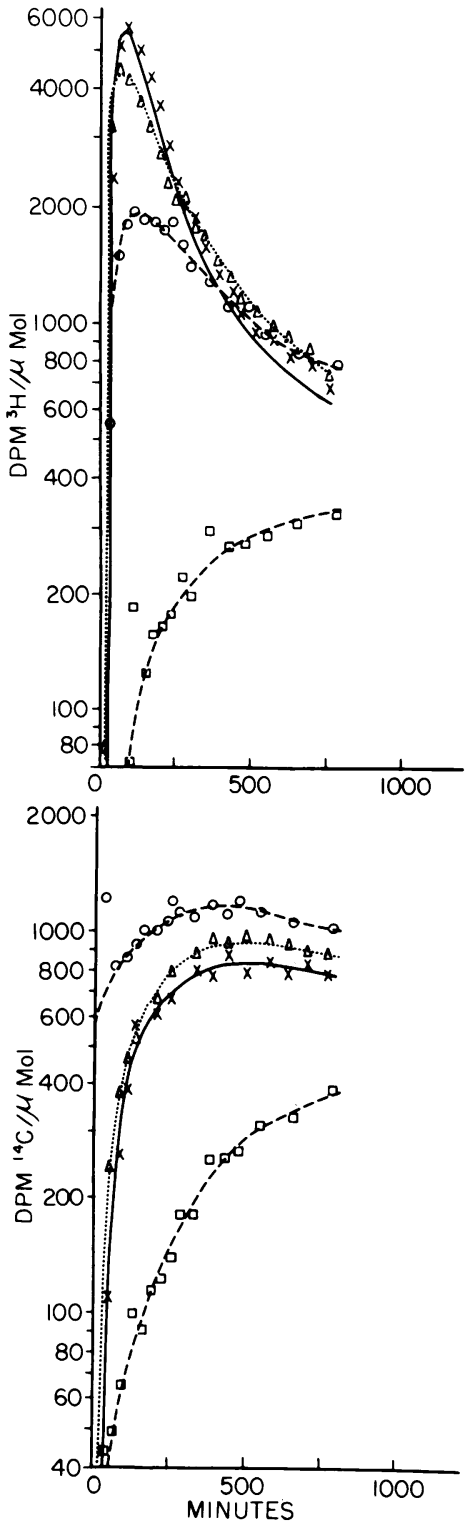

Figure 2 Specific activity time course after simultaneous administration of $\left[{ }^{3} \mathrm{H}\right]$ mevalonic acid (above) and $\left[{ }^{14} \mathrm{C}\right]$ cholesterol (below). Patient G. P. x, observed bile acid values; $\triangle$, observed biliary cholesterol values; $\bigcirc$, observed plasma free cholesterol values; $\square$, observed plasma esterified cholesterol values. The solid and dotted lines represent the predictions for the bile acid and biliary cholesterol values, respectively, derived from the simultaneous fitting of the ${ }^{3} \mathrm{H}$ and ${ }^{14} \mathrm{C}$ data to the model shown in Fig. 9. The dashed lines represent the forcing functions for the plasma free and esterified cholesterol. The residual error of the computer fits is expressed as the sum of squares/ number of data points: Biliary cholesterol, 117; bile acids, 281.

terol remained lower than the specific activity of the plasma free cholesterol.

The specific activity time course curves after 


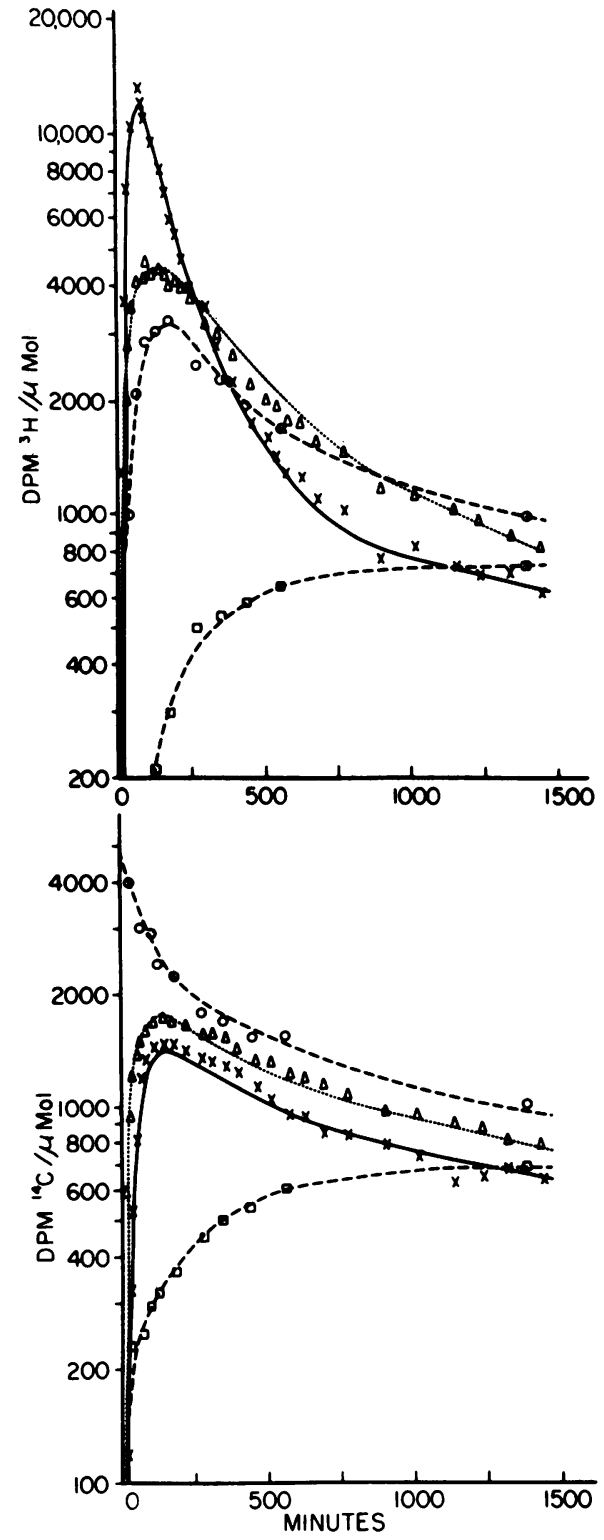

FIgURE 3 Specific activity time course after simultaneous administration of $\left[{ }^{3} \mathrm{H}\right]$ mevalonic acid (above) and $\left[{ }^{14} \mathrm{C}\right]-$ cholesterol (below). Patient P. C. For purposes of graphic clarity, only every third point for bile acids and biliary cholesterol are plotted during the first $480 \mathrm{~min}$. Residual errors: biliary cholesterol, 154; bile acids, 235. (See Fig. 2 for description of symbols, lines, and error.)

$\left[{ }^{14} \mathrm{C}\right]$ cholesterol administration also show a number of features common to all patients. These data also show the lack of a classic precursor-product relationship between the plasma free cholesterol, bile acids, and biliary cholesterol. The rate of buildup of ${ }^{14} \mathrm{C}$ activity in biliary cholesterol and bile acids was rapid, but the specific activities of these lipids never exceeded that of the plasma free cholesterol
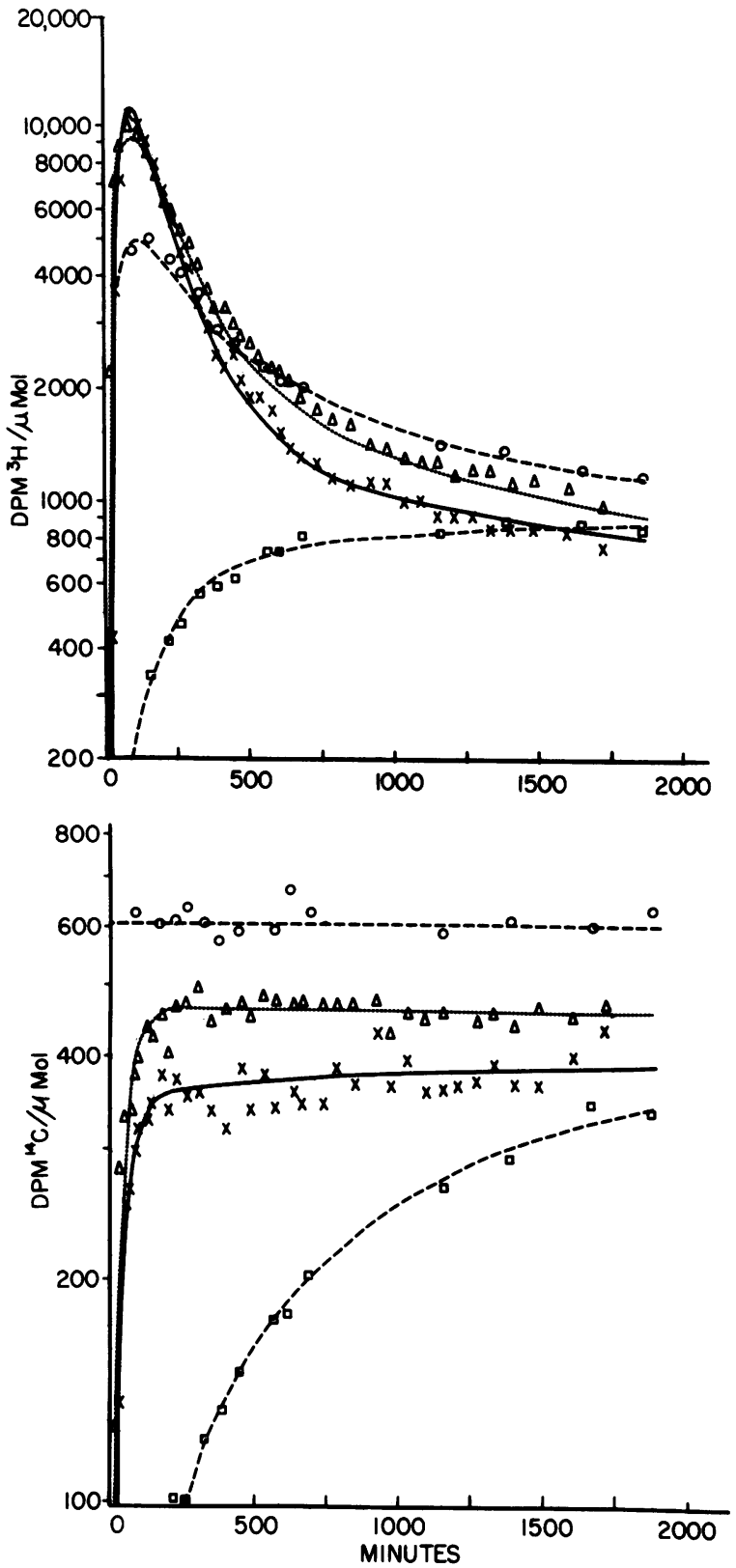

FIGURE 4 Specific activity time course after simultaneous administration of $\left[{ }^{3} \mathrm{H}\right]$ mevalonic acid (above) and $\left[{ }^{14} \mathrm{C}\right]-$ cholesterol (below). Patient L. C. For purposes of graphic clarity, only alternate points for bile acids and biliary cholesterol are plotted during the first $480 \mathrm{~min}$. Residual errors: biliary cholesterol, 145; bile acids, 200. (See Fig. 2 for description of symbols, lines, and error.)

during the course of the study. The specific activity of the plasma esterified cholesterol rose slowly in a manner analogous to that which was observed after isotopic mevalonic acid administration.

It was anticipated in the initial experiments that there would be a normal precursor-product relation- 

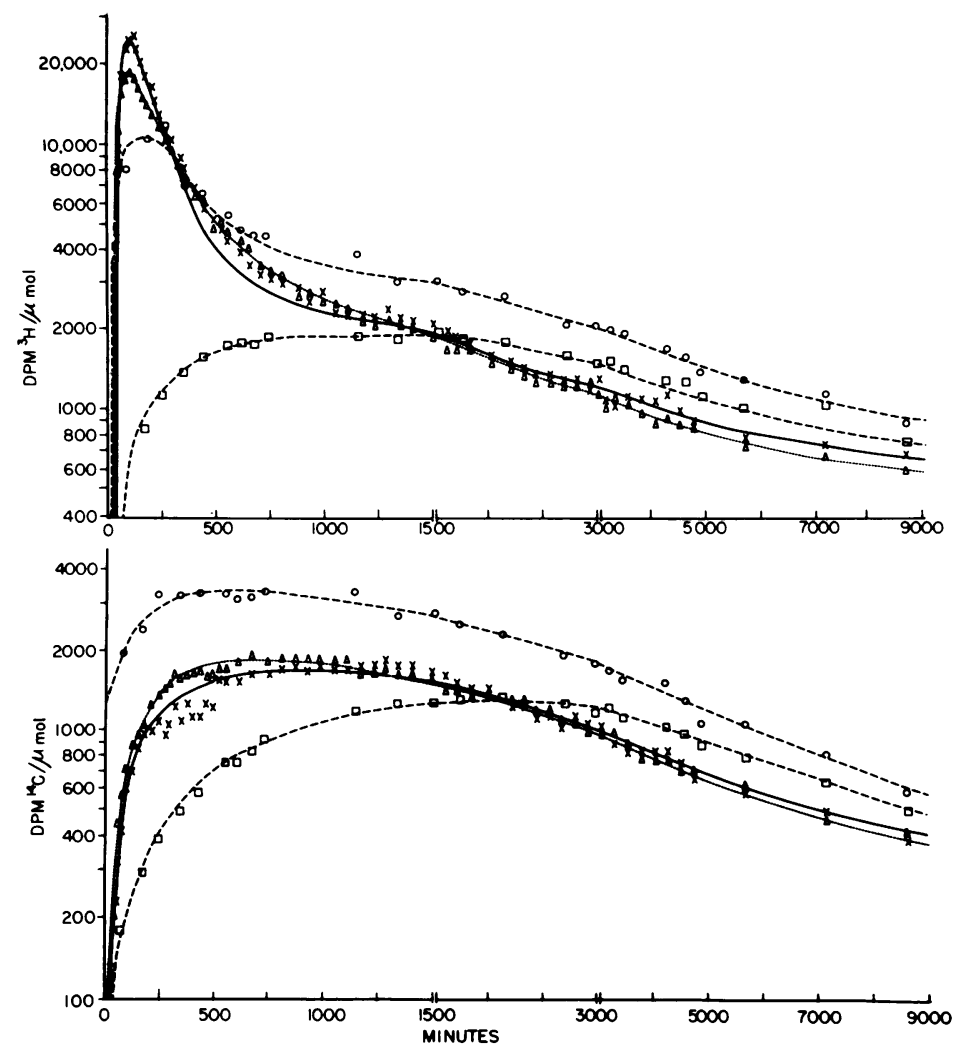

FIgURE 5 Specific activity time course after simultaneous administration of $\left[{ }^{3} \mathrm{H}\right]$ mevalonic acid (above) and $\left[{ }^{14} \mathrm{C}\right]$ cholesterol (below). Patient T. T. For purposes of graphic clarity, only alternate points for bile acids and biliary cholesterol are plotted during the first $480 \mathrm{~min}$. Residual errors: biliary cholesterol, 337; bile acids, 351. (See Fig. 2 for description of symbols, lines, and error.)

ship between the plasma free cholesterol (precursor) and the bile acids and biliary cholesterol (products), or that all fractions would have the same specific activities if they arose from a common hepatic site. This discordant behavior of the specific activities of the bile acid, biliary cholesterol, and plasma cholesterol fractions from that which would be expected from the three-compartment model as reported earlier (9) suggests that RMP does not provide an adequate description of the kinetic behavior of cholesterol in the liver, plasma, and extrahepatic tissues. These observations provided the impetus for the construction of a multicompartmental model to describe the kinetic behavior of the bile acid and biliary cholesterol data and also to provide quantitative information on cholesterol fluxes and pool sizes.

Development of the model. The following general assumptions are applicable to the development of the model: $(a)$ The patients were in a steady state with regard to hepatic and plasma cholesterol metabolism during the short time interval of the study. This condition was judged to be present by the relative constancy of the plasma free and esterified cholesterol concentrations and the bile acid and biliary cholesterol secretion rates (Tables I and II, Fig. 1). Although the presence of a total body steady state may not have been present, the use of a forcing function (described below) on the plasma cholesterol fractions, coupled with constant plasma and hepatic cholesterol pool sizes, permitted the modeling of the hepatic cholesterol compartments. (b) The administered particulate $\left[{ }^{14} \mathrm{C}\right]$ cholesterol which was phagocytized did not enter directly into the bile or the hepatocyte, but was released by the reticuloendothelial system into the plasma (29). The data of the present study support this assumption, since the specific activities of the bile acids and biliary cholesterol never exceeded that of the plasma free cholesterol after $\left[{ }^{14} \mathrm{C}\right]$ cholesterol administration. (c) The patients had a total bile fistula. This was evidenced by both the absence of secondary bile acids in the bile and the presence of acholic stools throughout the study period. (d) Cholesterol which is mobilized from extrahepatic tissues must enter the plasma free or esterified cholesterol compartments before entering the hepatocyte.

Since the specific activity data obtained in all six 

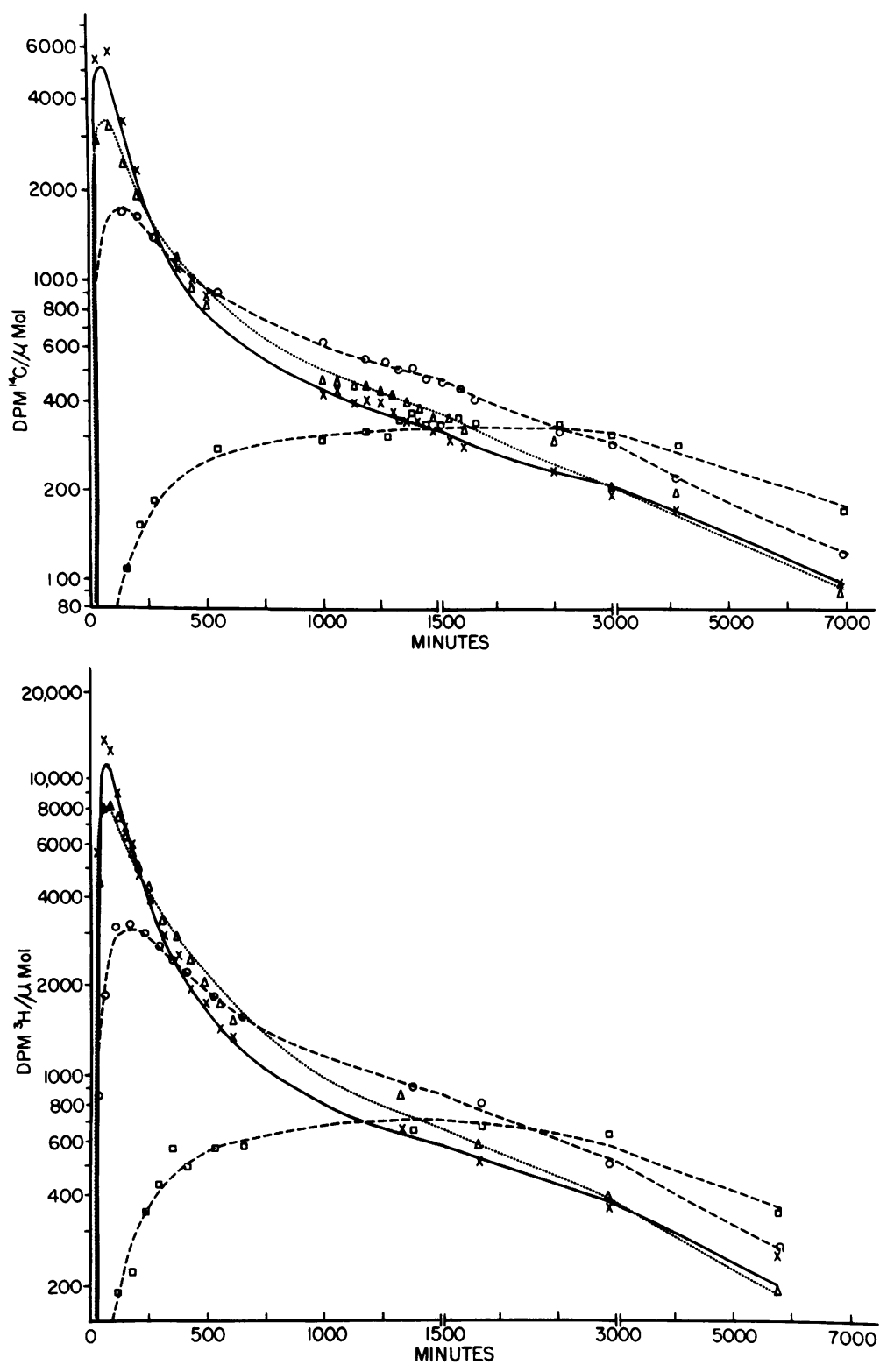

FIgURE 6 Specific activity time course curves. Patient $\mathrm{I}$. $\mathrm{H}$. initially received $\left[{ }^{14} \mathrm{C}\right]$ mevalonic acid (above) and then $18 \mathrm{~h}$ later received $\left[{ }^{3} \mathrm{H}\right]$ mevalonic acid (below). In this patient, the ${ }^{3} \mathrm{H}$ and ${ }^{14} \mathrm{C}$ data were fitted separately to the model shown in Fig. 9. Residual errors for ${ }^{3} \mathrm{H}$ data: biliary cholesterol, 3; bile acids, 9. Residual errors for ${ }^{14} \mathrm{C}$ data: biliary cholesterol, 25; bile acids 10. (See Fig. 2 for description of symbols, lines, and error.)

patients could not be interpreted in the light of the RMP concept of cholesterol metabolism in man, it was found necessary to construct a hypothetical model. Two base models were constructed as shown in Fig. $8 A$ and $B$ predicated on generally accepted pathways of cholesterol metabolism as follows: $(a)$ Bile represents the only significant route of cholesterol loss from the body. (b) Distinct hepatic cholesterol precursors $\left(\mathrm{C}_{2}\right.$ and $\left.\mathrm{C}_{3}\right)$ for the bile acids and biliary cholesterol were introduced consistent with the recently reported observations in man and rat $(13,15,20)$. Whether the biliary cholesterol precursor was an exchange compartment of the bile acid precursor or vice versa was tested as shown in model A vs. model $B$. The input of cholesterol into $\mathrm{C}_{2}$ and $\mathrm{C}_{3}$ can have multiple origins, namely hepatic $\operatorname{NSC}\left(\mathrm{C}_{1}\right)$ and (or) plasma free $\left(\mathrm{C}_{4}\right)$ cholesterol. $(c)$ The metabolism of plasma mevalonic acid has been well documented 


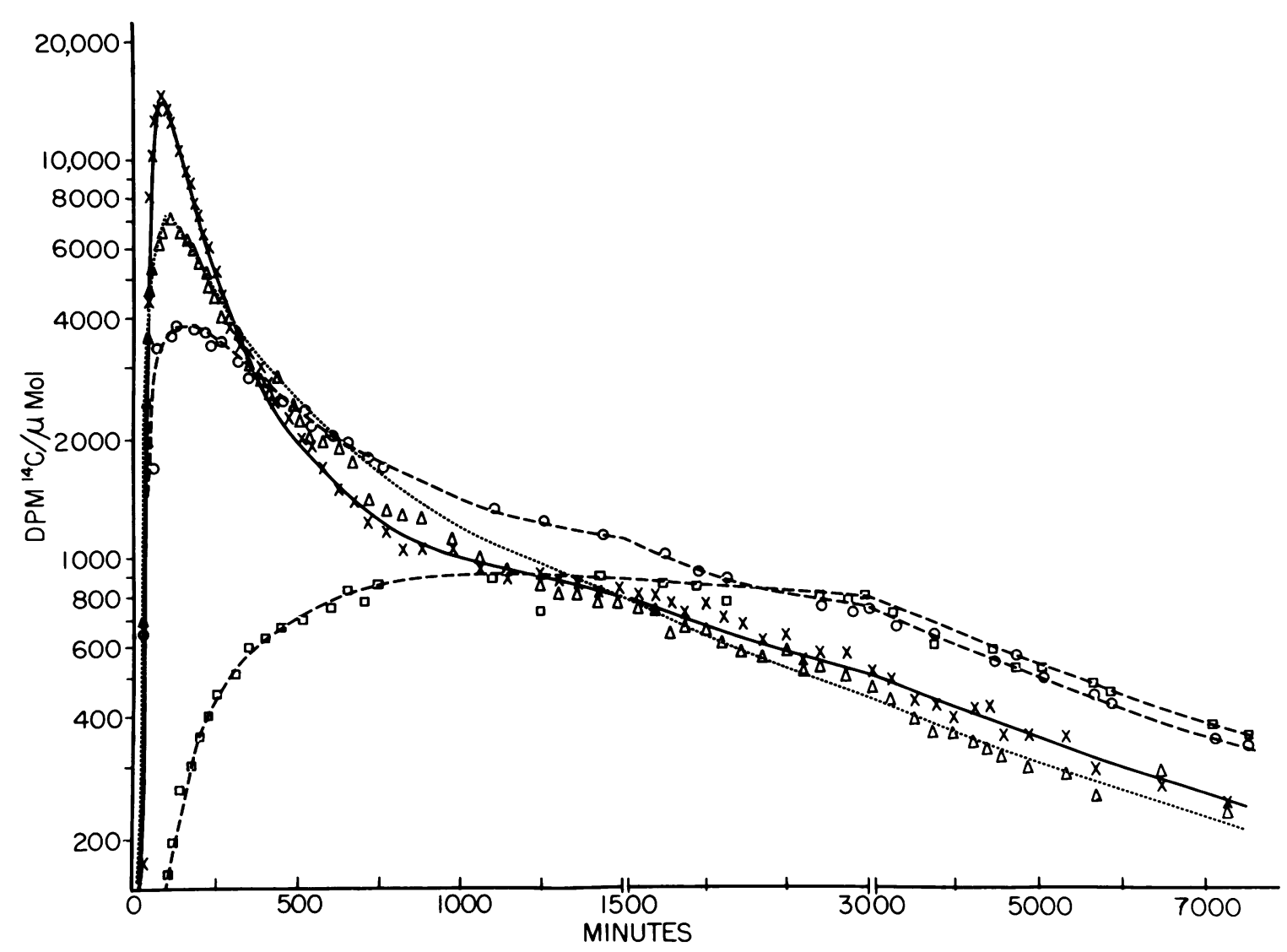

FIGURE 7 Specific activity time course after administration of $\left[{ }^{14} \mathrm{C}\right]$ mevalonic acid. Patient G. A. For purposes of graphic clarity, only alternate points for bile acids and biliary cholesterol are plotted during the first $480 \mathrm{~min}$. Residual errors: biliary cholesterol, 252; bile acids, 181. (See Fig. 2 for description of symbols, lines, and error.)

(35). Only the $\mathrm{L}$ form is metabolized, and the $\mathrm{D}$ form is excreted unchanged in the urine. A significant portion $(10-15 \%)$ of injected labeled mevalonic acid has been found to be converted to $\left[{ }^{14} \mathrm{C}\right] \mathrm{CO}_{2}$, probably via the trans-methylglutaconate shunt. By far, the major route of mevalonic acid metabolism is to sterols, which occurs in liver and extrahepatic tissues $\left(\mathrm{C}_{6}\right)$, as indicated in the base models. $(d)$ Since it is known that there is exchange between the plasma $\left(\mathrm{C}_{4}\right)$ and tissue $\left(\mathrm{C}_{6}\right)$ cholesterol, the appropriate exchange pathways have been introduced into the base model. It is also assumed that plasma esterified cholesterol $\left(\mathrm{C}_{5}\right)$ exchanges with the plasma free fraction $\left(\mathrm{C}_{4}\right)$.

The final multicompartmental model was arrived at by simulation analysis (28). The computer least-square fits were obtained after the model was evolved. During the model development, the least number of compartments and transport pathways were introduced consistent with the best fit of the data. In addition, the constraint was imposed that for any patient, the model fit the data obtained from both $\left[{ }^{14} \mathrm{C}\right]$ cholesterol and labeled mevalonic acid. In this context, the same parameter values were used to fit the data obtained from both tracers.

The boxes around compartments 4 and 5 indicate that they were used as forcing functions to lock down the specific activities of the free and esterified cholesterol leaving compartments 4 and 5 while modeling the liver subsystem. The forcing functions were derived by fitting the plasma free and esterified cholesterol specific activity curves to sums of exponentials. The use of these functions made it unnecessary to invoke exchange of cholesterol between the plasma compartments and extrahepatic tissues (compartment 6 in the models) in order to arrive at the present model.

In the base models, compartment 23 is designated as plasma L-mevalonic acid. Compartment 1 represents hepatocellular mevalonic acid or its product, NSC. For purposes of clarity, compartment 1 is designated as hepatic NSC. Transport pathways from compartment 1 to other compartments in the liver represent the flux of newly synthesized hepatic cholesterol.

Since the conditions for a steady state of hepatic and 
plasma cholesterol metabolism were present, the total cholesterol output from the system $\left(R_{0,2}\right.$ plus $\left.R_{0,3}\right)$ was set equal to the total input $\left(\mathrm{U}_{1}\right.$ plus $\left.\mathrm{U}_{6}\right)$. Accordingly, the minimum hepatic synthesis of cholesterol would be equivalent to the amount of NSC leaving compartment 1 and entering the bile acid and biliary cholesterol precursor sites $\left(R_{2,1}+R_{3,1}+R_{20,1}\right)$. This assumes no input of hepatic NSC into the plasma compartments $\left(R_{4,1}=0\right)$. In this case, the input of cholesterol into the plasma compartments would be via extrahepatic tissues (compartment 6 and $U_{6}$ ). Maximal cholesterol synthesis by the liver would be present if all the cholesterol input to the system occurred via hepatic synthesis $\left(U_{6}=0 ; U_{1}=R_{0,2}+R_{0,3}\right)$. Since the plasma cholesterol compartments were used as forcing functions and not modeled, the specific site(s) of origin of the plasma cholesterol was not pertinent at this stage of the model development. Therefore, the pathway from compartment 1 to compartment 4 $\left(R_{4,1}\right)$ is represented by a dashed line to indicate that this flux of cholesterol into the plasma probably represents a mixture of cholesterol synthesized by the liver and extrahepatic tissues.
The specific activity data were subjected to simulation analysis, using the base models shown in Fig. 8. Several features of the data were inconsistent with these base models: (a) radioactivity did not appear in the bile acids and biliary cholesterol as early as predicted; $(b)$ the specific activity of biliary cholesterol rose faster and reached its peak earlier than predicted by base model A; (c) bile acid specific activity rose faster and reached its peak earlier than predicted from base model $\mathrm{B}$; $(d)$ after the administration of $\left[{ }^{14} \mathrm{C}\right]$ cholesterol, the early portion of the decay of the bile acid specific activity was slower than predicted; $(e)$ after the administration of labeled mevalonic acid, the early portion of the decay of the biliary cholesterol specific activity curve was slower than predicted. These inconsistencies could not be eliminated by the adjustment of parameter values without introducing new inconsistencies. The first three inconsistencies were apparent after administration of either labeled compound. The first inconsistency was eliminated by the introduction of delays between the hepatic precursor compartments of bile acids and biliary cholesterol, and the outside.
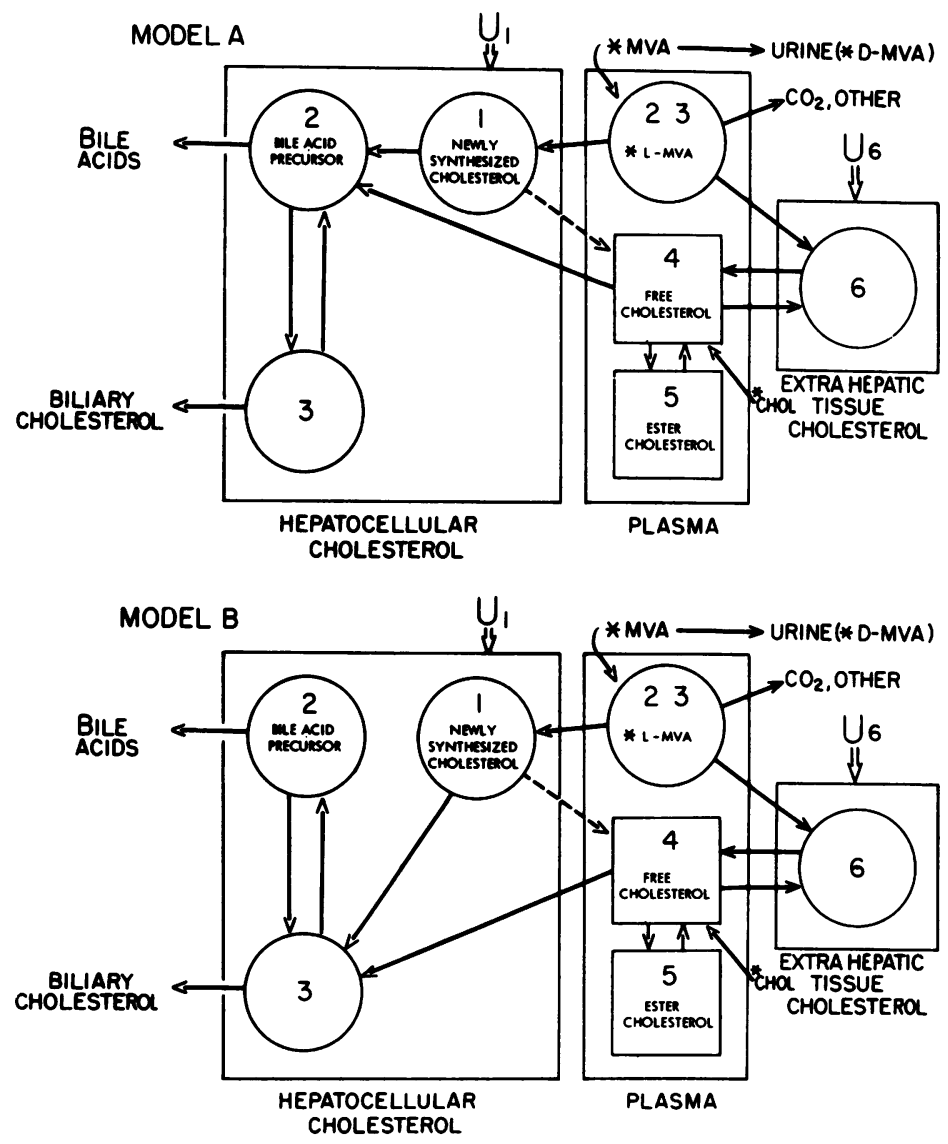

Figure 8 Base models $A$ and B. These models were used as starting points in the model development. *MVA, labeled mevalonic acid; CHOL, labeled cholesterol. 
These delays probably represent time consumed by biochemical processes and transport. The second and third inconsistencies suggested that the bile acid precursor compartment could not serve as the sole source for biliary cholesterol and vice versa. To obtain a fit of all the data, it was necessary to introduce transport pathways from hepatic NSC to both the bile acid and biliary cholesterol precursor compartments. A pathway was also required from the plasma free cholesterol compartment to both bile acid and biliary cholesterol precursor sites. The fourth inconsistency was resolved by introducing a pathway from the plasma cholesterol ester compartment to the bile acid precursor compartment. This does not imply that cholesterol ester enters directly into the bile acid precursor site, but probably undergoes hydrolysis upon entrance into the hepatocyte. The only successful alternative that was found to rectify the fifth inconsistency was the addition of a pathway from hepatic NSC to compartment 20, which then fed the biliary cholesterol precursor. The identity of compartment 20 is unknown. Several unsuccessful pathways were introduced in an attempt to solve the fifth inconsistency. Specifically, (a) a pathway to biliary cholesterol from the plasma ester compartment $\left(\mathrm{R}_{3,5}\right),(b) \mathrm{C}_{20}$ as an exchange compartment with $\mathrm{C}_{3}\left(\mathrm{R}_{20,3}\right.$ and $\left.\mathrm{R}_{3,20}\right)$, and $(c) \mathrm{C}_{20}$ in parallel with $C_{3}\left(R_{20,1}\right.$ and $\left.R_{10,20}\right)$ were tried and did not resolve the inconsistency. The fourth inconsistency was reexamined after the addition of $\mathrm{C}_{20}$, and it was observed that a pathway from $\mathrm{C}_{20}$ to $\mathrm{C}_{2}\left(\mathrm{R}_{2,20}\right)$ did not resolve the inconsistency which was resolved by $R_{2,5}$. The presence of pathways between the bile acid and biliary cholesterol precursor compartments, as shown in the base models, were eliminated because they did not improve the fit of the data. The inconsistencies were reexamined after the addition of each new pathway, and only those pathways were retained which were necessary to fit the observed data and resolve the inconsistencies.

The modified model arrived at by simulation analysis of the observed data is shown in Fig. 9. The computer fits of the bile acid and biliary cholesterol data to this model are indicated by the lines in Figs. 2-7.

Parameters of model. The steady-state fluxes between compartments and the interrelationships of selected interchanges are shown in Tables III and IV, respectively. The salient features are as follows: $(a)$ NSC furnished $31 \%$ and $20 \%$ of the respective total cholesterol flux into the bile acid and biliary cholesterol precursor compartments. (b) NSC directly accounted for $31 \%$ of the cholesterol lost in the bile as bile acids plus biliary cholesterol $\left(\mathrm{R}_{2,1}+\mathrm{R}_{3,1}+\mathrm{R}_{20,1}\right)$. (c) The

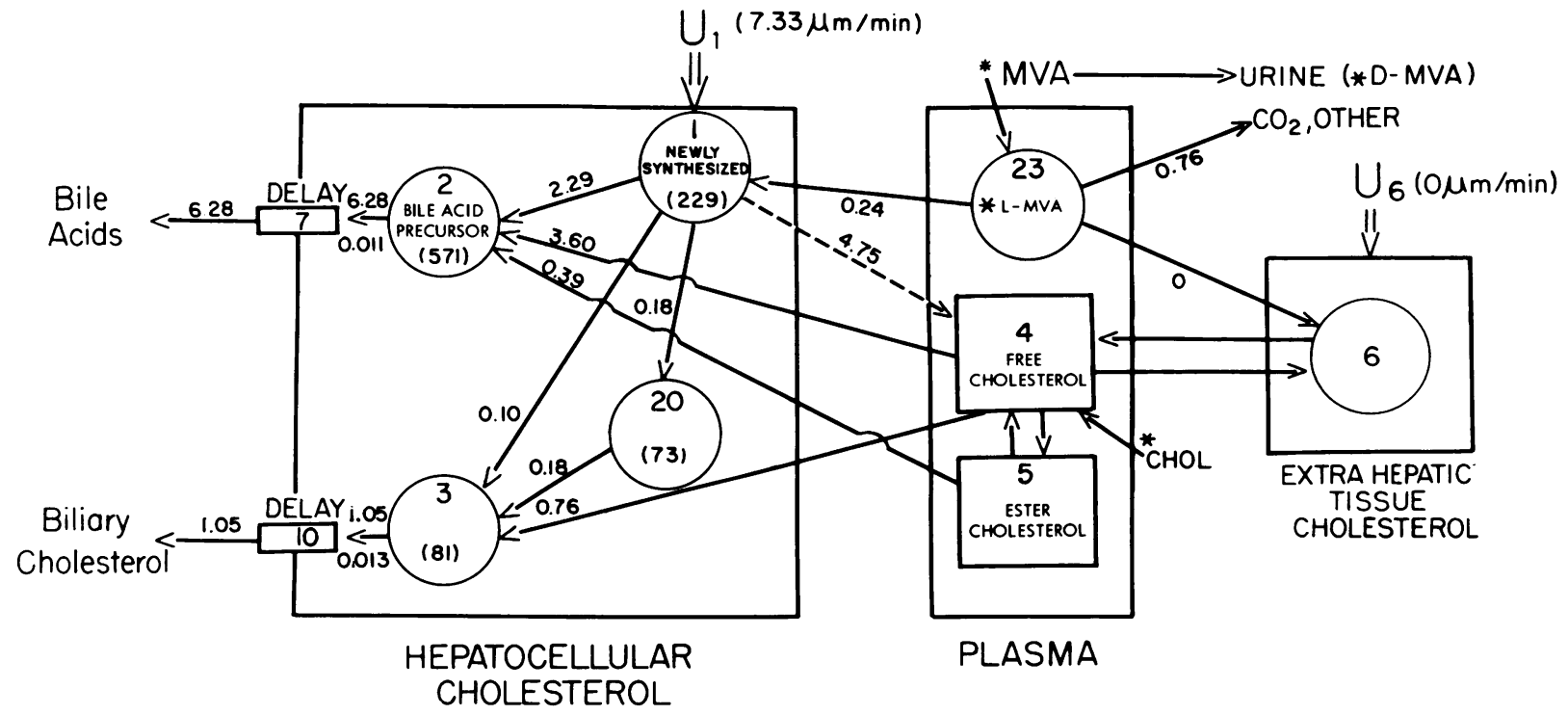

FIGURE 9 The modified model, including parameter values from a representative patient (P. C.). Rate constants $\left(\mathrm{min}^{-1}\right)$ are below the arrows. Fluxes (in micromoles per minute) are above the arrows. Values in parentheses inside a circle represent the calculated compartment in size in micromoles. The entire input of cholesterol mass has been arbitrarily placed into compartment 1 (maximum $U_{1}$ ). Compartments 4 and 5 were used as forcing functions as stated in the text and were not modeled. Compartment 6 , which represents extrahepatic tissue cholesterol, was also not modeled, but it is known to exchange with plasma free cholesterol. Preliminary modeling of $\mathrm{C}_{4}$ (unpublished observations) has similarly indicated exchange of cholesterol between $\mathrm{C}_{4}$ and $\mathrm{C}_{6}$. ${ }^{*} \mathrm{MVA}$, labeled mevalonic acid; $\mathrm{CHOL}$, labeled cholesterol. 
TABLE III

Steady-State Fluxes Derived from Compartmental Analysis

\begin{tabular}{|c|c|c|c|c|c|c|c|c|c|c|}
\hline Patient & $\mathrm{U}_{1}^{*}$ & $\mathbf{R}_{2,1}$ & $\mathrm{R}_{3.1}$ & $R_{4.1} \ddagger$ & $\mathrm{R}_{20,1} \S$ & $\mathrm{R}_{7,2}{ }^{\prime \prime}$ & $\mathbf{R}_{10,3^{\prime \prime}}$ & $\mathrm{R}_{2.4}$ & $\mathbf{R}_{3,4}$ & $\mathrm{R}_{2,5}$ \\
\hline & \multicolumn{10}{|c|}{$\mu \mathrm{mol} / \mathrm{min}$} \\
\hline G. P. & 8.71 & $1.05 \pm 11 \%$ & $0.41 \pm 13 \%$ & $7.18 \pm 2 \%$ & $0.08 \pm 37 \%$ & $6.14 \pm 4 \%$ & $2.57 \pm 9 \%$ & $4.30 \pm 5 \%$ & $2.09 \pm 10 \%$ & $0.80 \pm 19 \%$ \\
\hline P. C. & 7.33 & $2.29 \pm 4 \%$ & $0.10 \pm 11 \%$ & $4.75 \pm 2 \%$ & $0.18 \pm 12 \%$ & $6.28 \pm 2 \%$ & $1.05 \pm 9 \%$ & $3.60 \pm 2 \%$ & $0.76 \pm 10 \%$ & $0.39 \pm 31 \%$ \\
\hline L. C. & 7.42 & $1.78 \pm 4 \%$ & $0.17 \pm 10 \%$ & $5.42 \pm 1 \%$ & $0.05 \pm 22 \%$ & $6.49 \pm 1 \%$ & $0.93 \pm 8 \%$ & $3.74 \pm 2 \%$ & $0.71 \pm 9 \%$ & $0.98 \pm 10 \%$ \\
\hline T. T. & 4.80 & $1.41 \pm 5 \%$ & $0.36 \pm 10 \%$ & $2.81 \pm 2 \%$ & $0.22 \pm 11 \%$ & $3.53 \pm 3 \%$ & $1.27 \pm 9 \%$ & $1.75 \pm 4 \%$ & $0.69 \pm 9 \%$ & $0.37 \pm 18 \%$ \\
\hline I. H. $\left({ }^{3} \mathrm{H}\right)^{* *}$ & 5.53 & $1.66 \pm 8 \%$ & $0.25 \pm 16 \%$ & $3.54 \pm 4 \%$ & $0.08 \pm 75 \%$ & $4.53 \pm 2 \%$ & $1.00 \pm 9 \%$ & $2.39 \pm 8 \%$ & $0.67 \pm 11 \%$ & $0.48 \pm 42 \%$ \\
\hline I. H. $\left({ }^{14} \mathrm{C}\right)^{* *}$ & 5.53 & $1.52 \pm 5 \%$ & $0.23 \pm 18 \%$ & $3.71 \pm 2 \%$ & $0.08 \pm 104 \%$ & $4.52 \pm 2 \%$ & $1.01 \pm 9 \%$ & $2.50 \pm 5 \%$ & $0.70 \pm 10 \%$ & $0.50 \pm 90 \%$ \\
\hline G. A. & 5.18 & $1.32 \pm 3 \%$ & $0.22 \pm 16 \%$ & $3.55 \pm 1 \%$ & $0.09 \pm 36 \%$ & $4.26 \pm 2 \%$ & $0.92 \pm 9 \%$ & $2.48 \pm 4 \%$ & $0.61 \pm 10 \%$ & $0.47 \pm 70 \%$ \\
\hline
\end{tabular}

* Represents maximum value for $\mathrm{U}_{1}\left(\mathrm{R}_{7,2}+\mathbf{R}_{10,3}\right)$, assuming all cholesterol input to the system occurs via compartment 1 as hepatic synthesis $\left(\mathrm{U}_{6}=0\right)$.

$\$$ This flux can not be strictly interpreted as cholesterol entering the plasma free compartment from the liver, but as cholesterol entering the plasma compartment from liver and extrahepatic tissues (see text).

$\S R_{20,1}=R_{3,20}$.

" $\mathbf{R}_{7,2}=\mathbf{R}_{0,7}=$ total bile acid secretion rate $=$ total bile acid synthesis; $\mathbf{R}_{10.3}=\mathbf{R}_{\mathbf{0 . 1 0}}=$ biliary cholesterol secretion rate.

I Flux \pm relative standard deviation.

** Data independently derived from $\left[5-{ }^{3} \mathrm{H}\right]$ mevalonic acid $\left({ }^{3} \mathrm{H}\right)$ or from $\left[2-{ }^{14} \mathrm{C}\right]$ mevalonic acid $\left({ }^{14} \mathrm{C}\right)$.

major portion of the cholesterol entering the bile acid $(58 \%)$ and biliary cholesterol $(71 \%)$ precursor sites was derived from the plasma free compartment. $(d)$ The plasma ester compartment contributed $11 \%$ of the input into the bile acid site. (e) Also, compartment 20 made a small contribution $(10 \%)$ to the biliary cholesterol compartment.

The potential metabolic significance of the sources of cholesterol for the bile acid and biliary cholesterol precursor sites was examined by correlating a number of the fluxes. The rate of bile acid synthesis $\left(R_{7,2}\right)$ was highly correlated $(r=0.95)$ with the input of cholesterol from the plasma into the bile acid precursor site $\left(\mathrm{R}_{2,4}\right)$. There was no significant correlation between $R_{2,1}$ and $R_{7,2}$. Since five of the six patients had very similar biliary cholesterol secretion rates (Table II), no meaningful correlations between $R_{10,3}$ and the other fluxes could be obtained.

Derivation of the present cholesterol model in man has provided evidence for distinct pathways from the plasma free cholesterol compartment into biliary cholesterol and bile acids. Partitioning of cholesterol between these two pathways $\left(R_{2,4}\right.$ and $\left.R_{3,4}\right)$ may have important significance in determining the percentage of cholesterol in the biliary lipids, as suggested by the finding of a negative correlation $(r=0.96)$ between the ratio $R_{2,4} / R_{3,4}$ and the percent cholesterol in bile.

The rate constants derived from compartmental analysis are shown in Table $\mathrm{V}$. The turnover rate constant for the mevalonic acid compartment $\left(\mathrm{L}_{23,23}\right)$ was arbitrarily fixed at $1.0 / \mathrm{min}$, since a rate constant greater than $0.1 / \mathrm{min}$ had a negligible effect on the predicted bile acid and biliary cholesterol specific activities. The rate constants $\mathrm{L}_{2,4}, \mathrm{~L}_{3,4}$, and $\mathrm{L}_{2,5}$ have been omitted, since forcing functions were used on $\mathrm{C}_{4}$ and $\mathrm{C}_{5}$. The following points are pertinent: $(a)$ The turnover rate constants of the bile acid and biliary cholesterol precursor sites were similar; $(b)$ compart-

TABLE IV

Interrelationship of Steady-State Fluxes

\begin{tabular}{lcccccccc}
\hline \multicolumn{1}{c}{ Patient } & $\frac{\mathrm{R}_{2,1}}{\mathrm{R}_{7,2}}$ & $\frac{\mathrm{R}_{2,4}}{\mathrm{R}_{7,2}}$ & $\frac{\mathrm{R}_{2,5}}{\mathrm{R}_{7,2}}$ & $\frac{\mathrm{R}_{3,1}}{\mathrm{R}_{\mathbf{1 0 . 3}}}$ & $\frac{\mathrm{R}_{3,4}}{\mathrm{R}_{10,3}}$ & $\frac{\mathrm{R}_{3,20}}{\mathrm{R}_{\mathbf{1 0 . 3}}}$ & $\frac{\mathrm{R}_{2,4}}{\mathrm{R}_{3,4}}$ & $\frac{\mathrm{R}_{2,1}+\mathrm{R}_{3,1}+\mathrm{R}_{20,1}}{\text { Maximum }}$ \\
\hline G. P. & 0.17 & 0.70 & 0.13 & 0.16 & 0.81 & 0.03 & 2.06 & 0.18 \\
P. C. & 0.36 & 0.57 & 0.06 & 0.10 & 0.72 & 0.18 & 4.74 & 0.35 \\
L. C. & 0.27 & 0.57 & 0.15 & 0.17 & 0.78 & 0.05 & 5.42 & 0.27 \\
T. T. & 0.40 & 0.49 & 0.10 & 0.28 & 0.55 & 0.17 & 2.57 & 0.41 \\
I. H. $\left({ }^{14} \mathrm{C}\right)^{*}$ & 0.33 & 0.55 & 0.11 & 0.23 & 0.70 & 0.07 & 3.57 & 0.33 \\
G. A. & 0.31 & 0.58 & 0.11 & 0.24 & 0.67 & 0.10 & 4.07 & 0.31 \\
Mean & 0.31 & 0.58 & 0.11 & 0.20 & 0.71 & 0.10 & 3.74 & 0.31 \\
& \pm 0.03 & \pm 0.03 & \pm 0.01 & \pm 0.03 & \pm 0.04 & \pm 0.03 & \pm 0.52 & \pm 0.03 \\
\hline
\end{tabular}

* Data derived from $\left[2-{ }^{14} \mathrm{C}\right]$ mevalonic acid.

$\$$ Mean \pm SE. 
TABLE V

Rate Constants and Delay Times Derived from Compartmental Analysis*

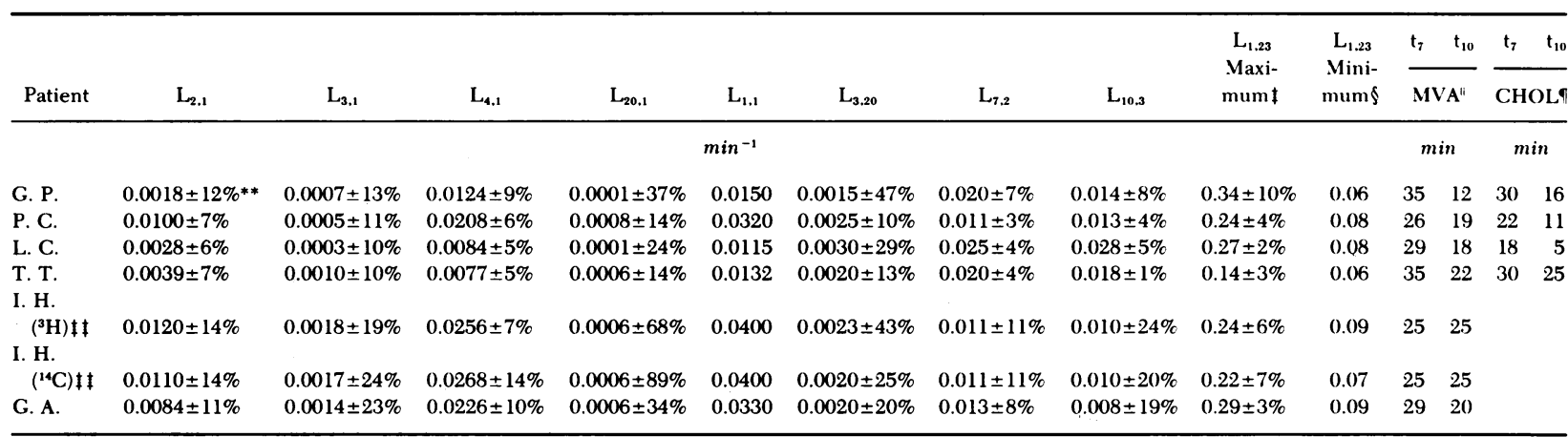

* Plasma mevalonic acid turnover $\left(\mathrm{L}_{23.23}\right)$ was fixed at $1.0 \mathrm{~min}^{-1}$ in all subjects.

I Fraction of isotopic L-mevalonic acid in compartment 23 converted to cholesterol in compartment 1 assuming maximum $U_{1}\left(U_{1}=R_{7,2}+R_{10.3} ; U_{6}=0\right)$.

$\$$ Fraction of isotopic L-mevalonic acid in compartment 23 converted to cholesterol in compartment 1 assuming minimum value for $U_{1}\left(U_{1}=R_{2.1}+R_{3.1}+R_{20,1}\right.$; $\mathbf{R}_{\mathbf{4}, 1}=0$ ). Relative standard deviations identical with corresponding maximum value.

"Delay time after isotopic mevalonic acid adminịstration.

I Delay time after isotopic cholesterol administration.

** Parameter \pm relative standard deviation.

If Data independently derived from $\left[5^{-3} \mathrm{H}\right]$ mevalonic acid $\left({ }^{3} \mathrm{H}\right)$ or from $\left[2-{ }^{14} \mathrm{C}\right]$ mevalonic acid $\left({ }^{14} \mathrm{C}\right)$.

ment 20 had the slowest turnover of the intrahepatic compartments; and $(c)$ the rate constants derived from the data obtained when patient I. $\mathrm{H}$. received either $\left[{ }^{3} \mathrm{H}\right]$ mevalonic acid or $\left[{ }^{14} \mathrm{C}\right]$ mevalonic acid were essentially identical. The delays in appearance of radioactivity in the bile acids and biliary cholesterol fractions of bile are also shown in Table $\mathrm{V}$.

The pool sizes obtained from compartmental analysis are shown in Table VI. These pool sizes represent a relatively small fraction of the estimated hepatic microsomal cholesterol pool.

\section{DISCUSSION}

This report has provided the basis for a new approach to the study of cholesterol metabolism in man. Development of the present cholesterol compartmental model would not have been possible without a suitable procedure for simulation analysis and modeling (SAAM27) (28), the T-tube patient, and the ability to introduce two labeled compounds and sample several cholesterol compartments simultaneously. Derivation of the model was based on a combination of current knowledge of cholesterol metabolism in man and an appropriate fit of the estimated parameters to the specific activity data. Only those interchanges (pathways) which were essential to obtain a good fit of the data were introduced into the model. The SAAM program also affords an opportunity for the introduction of biological delays and forcing functions. The latter allows for the locking down of radioactivity exiting a compartment equivalent to that actually observed. This has the advantage of isolating the liver from extrahepatic sources of cholesterol, since cholesterol leaving the tissues must first enter the plasma before exchange with the liver compartments.

Particularly pertinent to the validation of the present model was the administration of both isotopic mevalonic acid and $\left[{ }^{14} \mathrm{C}\right]$ cholesterol simultaneously to the same patient. First, isotopic mevalonic acid permitted the initial labeling of NSC (compartment 1) and subsequently the other compartments, while isotopic cholesterol (preformed) initially labeled plasma free cholesterol (compartment 4) and then the other compartments. This allowed for the labeling of the system at different sites simultaneously, which permitted the derivation of an internally consistent model. Second, in each of the patients that received both labeled compounds, good fits of the specific activity data (obtained from both mevalonic acid and cholesterol)

TABLE VI

Pool Sizes Derived from Compartmental Analysis

\begin{tabular}{lcrrrr}
\hline \multicolumn{1}{c}{ Patient } & $\begin{array}{c}\mathbf{M}_{1}{ }^{*} \\
\text { Maximum }\end{array}$ & $\begin{array}{c}\mathbf{M}_{1}{ }^{*} \\
\text { Minimum }\end{array}$ & $\mathbf{M}_{\mathbf{2}}$ & $\mathbf{M}_{3}$ & $\mathbf{M}_{20}$ \\
\hline & \multicolumn{5}{c}{$\mu \mathrm{mol}$} \\
G. P. & 581 & 102 & 307 & 184 & 50 \\
P. C. & 229 & 80 & 571 & 81 & 73 \\
L. C. & 646 & 174 & 260 & 33 & 15 \\
T. T. & 364 & 151 & 176 & 71 & 109 \\
I. H. $\left({ }^{3} \mathrm{H}\right) \downarrow$ & 138 & 45 & 412 & 100 & 36 \\
I. H. $\left({ }^{14} \mathrm{C}\right) \ddagger$ & 138 & 45 & 411 & 101 & 38 \\
G. A. & 157 & 50 & 328 & 115 & 47 \\
\hline
\end{tabular}

* Assume maximum or minimum $\mathrm{U}_{1}$ (see text).

\$ Data independently derived from $\left[5-{ }^{3} \mathrm{H}\right]$ mevalonic acid $\left({ }^{3} \mathrm{H}\right)$ or $\left[2-{ }^{14} \mathrm{C}\right]$ mevalonic acid $\left({ }^{14} \mathrm{C}\right)$. 
were observed from identical parameters. If there was appreciable recycled label from isotopic mevalonic acid, aberrations in the specific activity curves would have appeared which would have been incompatible with the fits obtained from $\left[{ }^{14} \mathrm{C}\right]$ cholesterol. Also, the use of mevalonic acid labeled at different sites, $\left[2-{ }^{14} \mathrm{C}\right]$ and $\left[5^{3} \mathrm{H}\right]$, in the same patient, which gave similar model solutions, discounts appreciable recycling of labeled mevalonic acid.

The findings of the present report have provided some new information on hepatic cholesterol metabolism in man. The derived model shows that liver and plasma cholesterol are not one homogenous pool (RMP), but rather that hepatic cholesterol is compartmentalized into definitive sites associated with the synthesis of bile acids and the secretion of biliary cholesterol. Both the bile acid and biliary cholesterol precursor compartments have inputs from NSC as well as from plasma free cholesterol. The proportioning of cholesterol into these sites from the plasma and NSC compartments was found to be approximately $2 / 3$ and $1 / 3$, respectively. Preliminary studies (unpublished observations) suggest that distinct precursor sites for bile acids and biliary cholesterol with inputs from the plasma and NSC are also present in the liver of the normal subject with an intact enterohepatic circulation. The contribution of NSC may be exaggerated in the bile fistula patient, since he has low plasma cholesterol levels and increased hepatic cholesterol synthesis. The present data are also in general agreement with studies in the rat which have shown that hepatic NSC is a substrate for bile acid synthesis (13-19). However, contrary to the findings in the bile fistula rat in which NSC is the major substrate, man with a bile fistula preferentially utilizes cholesterol from the plasma free compartment for bile acid synthesis.

The presence of definitive precursor pools for bile acids and biliary cholesterol raises some important questions regarding the control of hepatic cholesterol metabolism in man. It has been suggested that cholesterol secretion is independent of bile acid secretion (30). A possible explanation can be offered for these observations. The present findings suggest that bile acid synthesis $\left(\mathbf{R}_{7,2}\right)$ is closely related to the input of plasma free cholesterol into the bile acid precursor site $\left(R_{2,4}\right)$. This implies that the level of activity of hepatic $7 \alpha$-hydroxylase may regulate the entrance of cholesterol into the bile acid precursor pool. Cholesterol entering this site would then have only one excretory route, namely, conversion to bile acids. Since the major exit of cholesterol from the body is via the bile, the residual cholesterol which does not enter the bile acid precursor site must be secreted as biliary cholesterol. Thus, $7 \alpha$-hydroxylase may be at least one critical factor regulating the partitioning of plasma free cholesterol between bile acid synthesis and biliary cholesterol secretion. The other factor is the level of output of cholesterol from the plasma compartment $\left(R_{2,4}+R_{3,4}\right)$, which, when coupled with the activity of $7 \alpha$ hydroxylase, would determine whether bile will contain excessive cholesterol. Patient G. P., who had the highest percentage of cholesterol in his bile, illustrates how excessive cholesterol secretion may occur in the face of an inability to convert the major proportion of plasma free cholesterol to bile acids. Even though this patient had a high bile acid synthesis rate $(6 \mu \mathrm{mol} / \mathrm{min})$, an insufficient amount of rate-limiting enzyme was present in the microsomes to cope with the large influx of plasma free cholesterol. Therefore, the remaining cholesterol was secreted directly into bile, and this patient had the highest percent of cholesterol in bile and the lowest ration of $R_{2,4} / R_{3,4}$. Thus, lithogenic bile could result if there were insufficient $7 \alpha$-hydroxylase to cope with a normal output of cholesterol from the plasma, or if the output of cholesterol from the plasma increased without a compensatory increase in $7 \alpha$ hydroxylase, such as in obesity. It has been shown that obese patients $(31-33)$ have both increased cholesterol synthesis and secretion of biliary cholesterol. Other disorders of cholesterol metabolism induced by clofibrate administration, weight reduction, or Type IV hyperlipidemia may also fall into this category $(32,33)$.

Data were also obtained on the conversion of mevalonate to cholesterol in these bile fistula patients. The amount of radioactivity derived from isotopic mevalonic acid entering compartment 1 from compartment 23 was allowed to vary consistant with a good fit of the data. This amount was approximately $1 / 4$ of the isotopic L-mevalonic acid administered (in all patients). Stochastic analysis (34) of the individual specific activity curves gave virtually identical recovery of mevalonic acid. Complete urine collection during the period of study was obtained from two patients, and $50 \%$ of the administered DL- $\left[{ }^{3} \mathrm{H}\right]$ mevalonic acid was recovered. It is assumed that this $50 \%$ represented unmetabolized D-mevalonic acid. The fate of $3 / 4$ of the L-mevalonic acid is not known, but alternate pathways in the metabolism of L-mevalonic acid have been demonstrated in man (35). The same model parameters and the same fractional recovery of label were noted in patient I. H., who received both $\left[5-{ }^{3} \mathrm{H}\right]$ mevalonic acid and $\left[2-{ }^{14} \mathrm{C}\right]$ mevalonic acid.

The present investigation represents only the initial stage in the development of a multicompartmental model to study cholesterol metabolism in man. Additional studies are being carried out in subjects with an intact enterohepatic circuit. When the model has been elucidated in the normal subject, it should then be possible to more precisely define how cholic and chenodeoxycholic acids act to regulate the availability of their hepatic cholesterol precursors, to define the nature of the lipoprotein cholesterol precursor 
source(s), and to obtain important information on differences in cholesterol metabolism between healthy subjects and patients with hyperlipidemic disorders.

\section{ACKNOWLEDGMENTS}

This work was supported, in part, by U. S. Public Health Service research grant AM-14668 from the National Institute of Arthritis and Metabolic Diseases, National Institutes of Health, and the Veterans Administration.

\section{REFERENCES}

1. Grundy, S. M., and E. H. Ahrens, Jr. 1969. Measurements of cholesterol turnover, synthesis, and absorption in man, carried out by isotopic kinetic and sterol balance methods. J. Lipid Res. 10: 91-107.

2. Lindstedt, S. 1957. The turnover of cholic acid in man. Bile acids and steroids 51. Acta Physiol. Scand. 40: 1-9.

3. Vlahcevic, Z. R., J. R. Miller, J. T. Farrar, and L. Swell. 1971. Kinetics and pool size of primary bile acids in man. Gastroenterology. 61: 85-90.

4. Goodman, DeW. S., and R. P. Noble. 1968. Turnover of plasma cholesterol in man. J. Clin. Invest. 47: 221-241.

5. Nestel, P. J., H. M. Whyte, and DeW. S. Goodman. 1969. Distribution and turnover of cholesterol in humans. $J$. Clin. Invest. 48: 982-991.

6. Samuel, P., and W. Perl. 1970. Long-term decay of serum cholesterol radioactivity: body cholesterol metabolism in normals and in patients with hyperlipoproteinemia and atherosclerosis. J. Clin. Invest. 49: 346-357.

7. Samuel, P., and S. Lieberman. 1973. Improved estimation of body masses and turnover of cholesterol by computerized input-output analysis. J. Lipid Res. 14: 189- 196.

8. Goodman, DeW. S., R. P. Noble, and R. B. Dell. 1973. Three-pool model of the long-term turnover of plasma cholesterol in man. J. Lipid Res. 14: 178-188.

9. Smith, F. R., R. B. Dell, R. P. Noble, and DeW. S. Goodman. 1976. Parameters of the three-pool model of the turnover of plasma cholesterol in normal and hyperlipidemic humans. J. Clin. Invest. 57: 137-148.

10. Quarfordt, S. H., and M. F. Greenfield. 1973. Estimation of cholesterol and bile acid turnover in man by kinetic analysis. J. Clin. Invest. 52: 1937-1945.

11. Nestel, P. J., and B. Kudchodkar. 1975. Plasma squalene as an index of cholesterol synthesis. Clin. Sci. Mol. Med. 49: $621-624$.

12. Liu, G. C. K., E. H. Ahrens, Jr., P. H. Schreibman, P. Samuel, D. J. McNamara, and J. R. Crouse. 1975. Measurement of cholesterol synthesis in man by isotope kinetics of squalene. Proc. Natl. Acad. Sci. U. S. A. 72: 4612-4616.

13. Staple, E., and S. Gurin. 1954. The incorporation of radioactive acetate into biliary cholesterol and cholic acid. Biochim. Biophys. Acta. 15: 372-376.

14. Ogura, M., J. Shiga, and K. Yamasaki. 1971. Studies on the cholesterol pool as the precursor of bile acids in the rat. $J$. Biochem. 70: 967-972.

15. Cronholm, T., A. L. Burlingame, and J. Sjövall. 1974. Utilization of the carbon and hydrogen atoms of ethanol in the biosynthesis of steroids and bile acids. Eur. J. Biochem. 49: 497-510.

16. Mitropoulos, K. A., N. B. Myant, G. F. Gibbons, S.
Balasubramaniam, and B. E. A. Reeves. 1974. Cholesterol precursor pools for the synthesis of cholic and chenodeoxycholic acids in rats. J. Biol. Chem. 249: 6052-6056.

17. Normann, P. T., and K. R. Norum. 1976. Newly synthesized hepatic cholesterol as precursor for cholesterol and bile acids in rat bile. Scand. J. Gastroenterol. 11: 427-432.

18. Balasubramaniam, S., K. A. Mitropoulos, and N. B. Myant. 1973. Evidence for the compartmentation of cholesterol in rat-liver microsomes. Eur. J. Biochem. 34: 77-83.

19. Bjorkhem, I., and H. Danielsson. 1975. $7 \alpha$-Hydroxylation of exogenous and endogenous cholesterol in ratliver microsomes. Eur. J. Biochem. 53: 63-70.

20. Schwartz, C. C., Z. R. Vlahcevic, L. G. Halloran, D. H. Gregory, J. B. Meek, and L. Swell. 1975. Evidence for the existence of definitive hepatic cholesterol precursor compartments for bile acids and biliary cholesterol in man. Gastroenterology. 69: 1379-1382.

21. Folch, J., M. Lees, and G. H. Sloane-Stanley. 1957. A simple method for the isolation and purification of total lipides from animal tissues. J. Biol. Chem. 226: 497509.

22. Bartlett, G. R. 1959. Phosphorus assay in column chromatography. J. Biol. Chem. 234: 466-468.

23. Sperry, W. M., and M. Webb. 1957. A revision of the Schoenheimer-Sperry method for cholesterol determination. J. Biol. Chem. 187: 97-106.

24. Swell, L. 1968. Separation, identification, and estimation of radioactive and nonradioactive lipids. In Theory and Application of Gas Chromatography in Industry and Medicine. H. S. Kroman and S. R. Bender, editors. Grune \& Stratton, Inc., New York. 97-109.

25. Goad, L. J. 1970. Sterol biosynthesis. Biochem. Soc. Symp. 29: 45-77.

26. Schwartz, C. C., B. I. Cohen, Z. R. Vlahcevic, D. H. Gregory, L. G. Halloran, T. Kuramoto, D. H. Mosbach, and L. Swell. 1976. Quantitative aspects of the conversion of $5 \alpha$-cholestane intermediates to bile acids in man. J. Biol. Chem. 251: 6308-6314.

27. Hirsch, J., and E. H. Ahrens, Jr. 1958. The separation of complex lipide mixtures by the use of silicic acid chromatography. J. Biol. Chem. 233: 311-320.

28. Berman, M., and M. F. Weiss. 1974. SAAM Manual (revised). U. S. Department of Health, Education and Welfare, Public Health Service, Government Printing Office, Washington, D. C.

29. Nilsson, A., and D. B. Zilversmit. 1972. Fate of intravenously administered particulate and lipoprotein cholesterol in the rat. J. Lipid Res. 13: 32-37.

30. Swell, L., D. H. Gregory, and Z. R. Vlahcevic. 1974. Current concepts of the pathogenesis of cholesterol gallstones. Med. Clin. North Am. 58: 1449-1471.

31. Bennion, L. J., and S. M. Grundy. 1975. Effects of obesity and caloric intake on biliary lipid metabolism in man. $J$. Clin. Invest. 56: 996-1011.

32. Grundy, S. M. 1976. Dietary and drug regulation of cholesterol metabolism in man. Med. Chem. 2: 127-159.

33. Miettinen, T. A. 1976. Methods for evaluation of hypolipidemic drugs in man: mechanisms of their action. Med. Chem. 2: 83-125.

34. Shipley, R. A., and R. E. Clark. 1972. Tracer Methods for In Vivo Kinetics. Academic Press, Inc., New York.

35. Fogelman, A. M., J. Edmond, and G. Popjak. 1975. Metabolism of mevalonate in rats and man not leading to sterols. J. Biol. Chem. 250: 1711-1775. 